\title{
Self-Consciousness Issues in Modern Society. Changes in Public Life and Its Impact on the Social Self-Conscience. The Self-Consciousness Issue in Multicultural Society
}

\author{
Lyazzat llimkhanova
}

PhD doctoral candidate, Independent Scientist - researcher,

Email:lyazzat.ilimkhanova@gmail.com

\section{Mukhan Perlenbetov}

Doctor of Psychological Sciences; professor and vice-rector of Kainar University; academician of the Kazakh National Academy of Sciences.

Email:phd2014.kz@gmail.com

\section{Mergenbai Kurganbekov}

KazNPU after Abai.

Email:phd2014.kz@gmail.com

Meruert Assylkhanova

Candidate of Psychological Sciences KazNPU after Abai.

Email:phd2014.kz@gmail.com

Saltanat Tazhbayeva

Candidate of Psychological Sciences KazNPU after Abai

Email: saltanat.tazhbay@mail.ru

\section{Sanim Kozhayeva}

Candidate Teacher of Pedagogical Sciences KazNPU after Abai. Email:phd2014.kz@gmail.com

Gulbanu Saduakas

Teacher, phd2014.kz@gmail.com

Darazha Issabayeva

Candidate of Pedagogical Sciences KazNPU after Abai. Email:phd2014.kz@gmail.com

Doi:10.5901/mjss.2014.v5n20p2574

Abstract

In the course of its XXth century development, the Russian society came to know opposite trends in terms of the political, ideological, social and economic transformation stages. This is the result of transition from the social and economic identification to the ethno-social one. The numerous researches performed showed that identifying the reasons of these aspects would be possible after a more detailed examination of principles referring to the investigation of both national and general self-consciousness of the Russian society individuals. The result of the investigation is the evaluation of the Russian society general self-consciousness and the problem of its transformation under the influence of the Russian state policy changes. The purpose of this process is identifying solutions to current problems and minimizing risks of the selfconsciousness instability and personal identity conflict.

Keywords: reference context, consciousness, individual self-consciousness, social environment, knowledge, experience, globalization, approach, behavior, ethnic group, peculiarities, psychology, pedagogy. 


\section{Introduction}

As historical experience shows, the self-consciousness transformations represent an incentive for the achievement by nation of great social performance, but they can also become a reason for the national tragedy. In this context, studying the self-consciousness peculiarities and its emergence conditions is the social thinking important task. Variability and reference context of the self-consciousness matter and its expression forms represent a topical research issue within the multiethnic country environment resulting from social, cultural and political changes aimed at the federal, legal and democratic state development

The emerging Russian national identity environment yielded an objective demand for new stabilizing elements. This demand is characterized by a larger scientific use of such notions as "national cause", "national interests", "consent". During the critical epochs, changes in the individual self-consciousness value trends marked the relevance of new ideas emergence viewed as a direct necessity in the context of the nation basis strengthening.

The present situation is excessively characterized by an insufficiency of the philosophic reasoning of inter-ethnic relations and nation development. The analysis process involves not only sociology, but also psychology and many other sciences for a more complex approach to the issue settlement. For this reason, there is a discontinuity in research, wherein the empirical element is emphasized and the theoretical terms are politicized. Obviously, a further multi-faceted philosophic development of the national specificity issues, as well as of the self-consciousness transformation patterns is needed. This would incite the private research and theoretical patterns further development for an efficient analysis of the personality change consequences. The national philosophy requires an improvement in approaches and views on the nature, structure, essence, mechanisms, functions, levels and regularity of the self-consciousness emergence. There is need in an advanced study and generalization of social and philosophic matters, as well as a theoretical understanding of the issues themselves, as the self-consciousness change determinant.

National self-consciousness as the determinant factor of the personality self-consciousness development

The personality self-consciousness development within a multicultural society is based on the country population spiritual culture: its sphere of concepts and language, behavior norms and values, the total of the human reason and nature creations: profane and sacral, reasonable and mythological, contemporary and traditional. Every social environment makes an assertive contribution to the general idea development. This environment is characterized by complexity and it consists of different culture types. Its existence is based on inter-culture and -subculture communication. The self-consciousness issue refers to this communication issue.

The self-consciousness content mainly consists in a certain country inhabitants' perception of the social and cultural community holding a certain place among other communities coexisting in the world and in the country, in particular. Large sections of the Russian state population are characterized by archaic and contemporary selfconsciousness patterns, developing in parallel. Consequently, many researchers face a great challenge of re-thinking the existent patterns not meeting the modern society requirements, this challenge resulting from the country condition and long standing problems.

National self-consciousness impact on the tolerant inter-ethnic communication development by the example of the neighboring states within the post-Soviet area. Integration of new inter-ethnic relations stabilization patterns by the example of Kazakhstan.

The main problem referring to the Kazakhstan reality is the impossibility to implement Western models for the country social order improvement in conditions of the unitary state. At least, this fact is proved by the international experience: there was no and there is no equal bilingualism (or multilingualism) in any of the unitary states.

If a certain part of the population neither speaks nor understands the native language of the other part, then any person speaking in public or writing in Kazakh, will actually address not to all the Kazakhstani, but only to those who understand this language, that is mainly the ethnic Kazakhs. In other words, any person either speaking or writing in Kazakh actually addresses to ethnically homogeneous audience. This, in its turn, has an obvious impact on the content of the issues pronounced or written - both the subject and sphere of the notions used. In addition, the concept of political correctness limits is also subject to changes. For instance, the use of certain "politically incorrect" expressions becomes practically unavoidable in case the copywriter addresses to his ethnic compatriots (in this case Kazakh to Kazakhs), knowing beforehand that the others not only "will not hear", but also "will not listen" to him.

To overcome this trend, it is necessary again that the Russian-speaking population, at least the young, learns the state language in a relatively short time. Such prospects may become real provided that this social class is ready for its self-consciousness transformation - that is, change in priorities, wherein the Russian language "ranking first" in their opinion would give way to the Kazakh language.

Thus, the strategic purpose shall be well-perceived - that is turning the Kazakh language into a really functional, 
generally dominating state language, and the inter-ethnic communication language in prospect. To be more precise, the question in no way refers to cancellation of the Russian language official status - it refers to the prospective analogy of the "Finnish model". The results of the survey performed are very interesting. In all, there have been interviewed 1200 persons from all Kazakhstan regions.

Analysis of respondents' answers to the question "What language do you think in?" showed that: $41.6 \%$ think in Kazakh, including, by age: - 42,8\% aged 16 and older; by nationality: - among the Kazakhs interviewed - 59,7\%, among the Russians interviewed - 13,2\%, among the Uzbeks interviewed - 14,8\%, among the Ukrainians interviewed - 17,5\%, among the Tatars interviewed $-20,0 \%$, among the Germans interviewed $-6,7 \%$ and among the representatives of other nationalities interviewed - 7,1\%; by regions: - among the Almaty region inhabitants interviewed - 63,5\%, among the South-Kazakh region inhabitants interviewed - 54,8\%, among the East-Kazakh region inhabitants interviewed - 48,4\%, among Astana city inhabitants interviewed - 46,7\%, among the Pavlodar region inhabitants interviewed $-5,5 \%$ and among the other regions inhabitants interviewed - from $39,5 \%$ to $25,6 \%$;

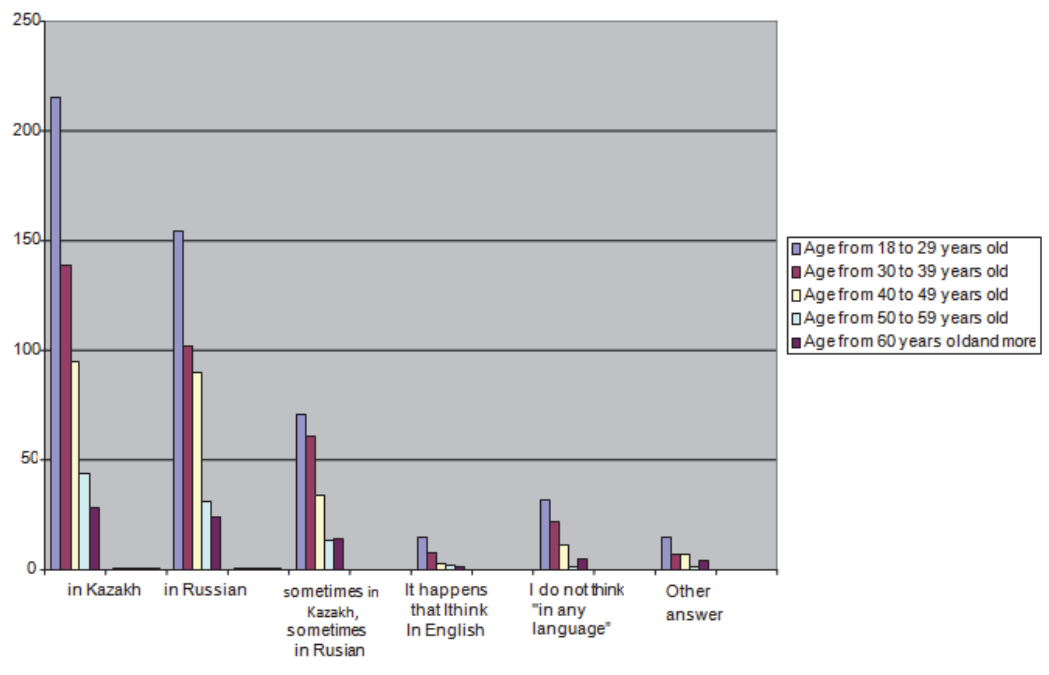

Thus, this example clearly shows solutions to poly-cultural and multinational society problems and the personality selfconsciousness transformation in the context of continuous changes applied to the inter-ethnic communication environment.

\section{Research \& Results}

The Russian people self-consciousness development patterns shall be considered unique. Thus, for instance, S.A. Nikolsky (D.P.S. IP RAS, Moscow) emphasized the significance of the "Russian worldview" different from the Western world perception. In particular, the determinant of "grief" was examined. The suggestion to study this conceptual category through Russian literature closely related to the Russian philosophy found a broad response among contemporary researchers. Besides, Nikolsky suggested that the patterns deeply-rooted in minds are modified and the multiple mythologems, such as the Russian laziness, are disputed. Concrete historical facts shall be considered as the refutation to this popular misbelief. Thus, in the period of 1921-1929 the new economic policy of Bolsheviks resulted in the double increase of the agrarian products volume in Russia. At the same time, the society social order was subject to transformations. In the course of this period, the ratio of the medium peasants and kulaks to the poor changed from 20:80 to 60:40. Such transformations within the society had certain consequences, and namely the split effect adherent to the Russian self-consciousness till the mid of the XIXth century. At this stage, the era of the Western society development patterns implementation began; these patterns became the basis of the industrial revolution. Objectively, up to this historical stage the Russian people self-consciousness was the consciousness of farmers, irrespective of their hierarchic and birth statuses.

Research was based on statistical data, which showed: in 1917,13mln. people of Russia inhabitants were part of the poor social class, $4 \mathrm{mln}$. were part of the medium peasants class, $3 \mathrm{mln}$. were part of the kulaks class. This trend 
changed in the course of one decade, and in 1928 the number of "the poor" representatives was $8.7 \mathrm{mln}$, "the medium peasants" - $15 \mathrm{mln}$, "the kulaks" - $1.1 \mathrm{mln}$.

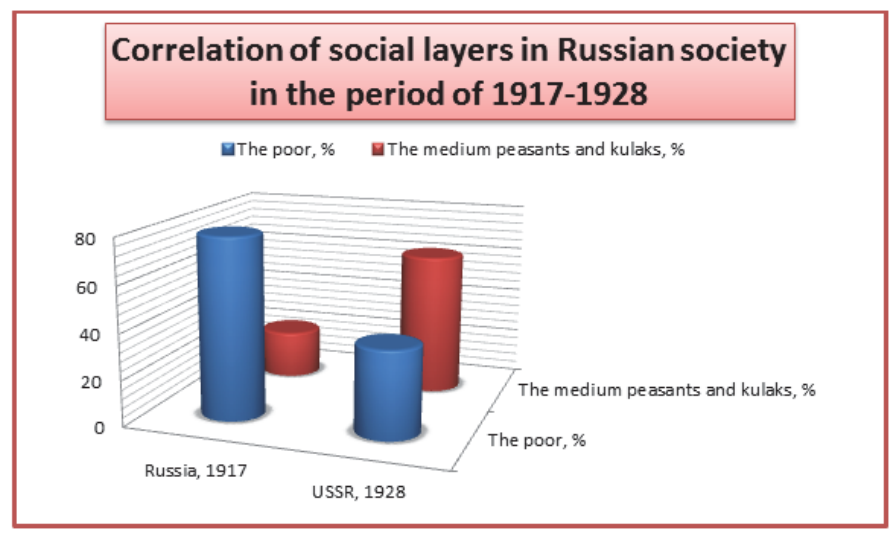

Works and reports of V.M. Mejuev reflect several trends in the Russian society self-consciousness issues study. In author's opinion, understanding the civilizational affiliation to Russia is necessary. For example, there is no dispute among the Europeans on their affiliation to either one civilization or another.

In Mejuev's opinion, the problem of Russian self-consciousness consists in abnegation. Every consequent period of development and transformation in Russian history marks the negation of the previous one. Thus, Moscovia buried the Novgorod Russia, while the St.Petersburg Russia developed on ruins of Moscovia culture. Similarly, the Soviet Russia did not recognize the Russian Empire heritage. Even the contemporary Russia development is based on negation of the soviet period cultural achievements.

The researcher emphasized the importance of defining the self-consciousness subject and giving an answer to the question - is it adherent to Russia in terms of people's minds or in terms of the state itself? Obviously, the Russian nation collective perception of itself is based on the Russian culture rather than experience, values, etc. Nevertheless, the ethnic self-consciousness is not the same as the national one. In this context, there is a differentiation paradigm - the ethnic factor refers to difference, the national one refers to unification. The Russian people self-consciousness evolved through many centuries on a community basis. Even in this case, there is an obvious difference between the Europeans united in terms of "reason", "science" and the Slavs united on a "religious" basis - Christianity. Modern globalization is essentially different from this approach and it incites many questions and inadequacy in the Russian society environment.

Analysis of the self-consciousness notion according to Hegel shows that the Russian idea itself is inexpressive in this context. Knowledge based on faith rather than the historical facts and empirical data is defined as the religious and philosophic knowledge. For this reason, the Russian consciousness notion and context is logically beyond expression. Another peculiarity consists in the fact that ethnicism and eurocentrism are unacceptable in Russia, as the Russian culture did not originally emerge as an ethnic one. The Russian idea is characterized by general humanism and negation of the national interest concept, as its foundation is the Orthodox ethics based on individual redemption, sacrifice, etc. This marks the impossibility of the Russian self-consciousness traditional evaluation and research, improved approaches being necessary.

In this context, the analysis and conclusion made by A.V.Rubtsov are remarkable. He contributed to the development of the theoretical and applied literature, reflecting evaluation of Russian self-consciousness notion. In his opinion, the "national idea" is one of the most influential self-consciousness determinants, yielding the individual selfidentification phenomenon through "another individual". Thus, if a European is neither Turk nor Russian, then the Russians faced significant transformations on the way towards self-identification. In Petrine Russia, the Russian is neither Tatar nor German, in the XIXth century - he is French neither, and later on - he is neither Polack, nor Ukrainian. In the USSR period, Russians identified themselves as neither Jewish, nor foreigners. During the "cold war" period the Soviet people were considered Russians by the Westerners, irrespective of whether they were Georgians, Kazakhs, Jews or Ukrainians. This trend is still present in Western countries - not citizen of Russia, Ukraine, etc, but "Russian". 


\section{Discussion}

The Russian self-consciousness paradox is relevant, this issue being continuously studied by specialists. Thus, A.A. Kara-Murza and N. Berdyaev noticed a certain phenomenon. Russia, being the most "nationalist" may also become the most "universalist" country in the world. It extensively confirms its absolute uniqueness and distinctiveness, but also its absolute identity to world. Stable contradiction between universalism and uniqueness is one of the most significant Russian self-consciousness constants. This allowed Kara-Murza emphasize archaic, politicized unilateral grounds and conceptions of both the "cosmopolitan universalism" and "national exclusiveness" of Russia, still existent today. In this situation, a multilateral approach and detailed analysis of the "interaction" process between the "universal" and the "distinctive" in Russian culture is needed.

\subsection{Reforms as the self-consciousness development determinants}

Reforms have a great impact on the emergence of the individual values and cultural behavior patterns, as well as on the self-consciousness setting up. Namely reforms revealed the social mechanisms' depreciation and their non-conformity to social interests, as well as the obvious limits of the disputes worked out. Reforms set the limits to naive expectations for the nation basic inexhaustible moral and spiritual resources, liberal ideas, and legal groundwork for consent in society, as the basis for democracy. Consequently, the political elite, namely the pragmatic part of it, collected a majority promoting the "pure" great power statehood idea, in the context of no resistance from opposition. This conception was considered as the main national idea. Nevertheless, this trend was only a short-term phenomenon, an intermediate phase in the Russian society social evolution process. As practice shows, the natural unity between power and nation, society and state may become a stable model of the sociologic development based on other factors. For this purpose, it is necessary to exclude the national idea from mindset.

Comparability of the Russian and European worldview and self-consciousness from the teleological viewpoint allows demarcating the differences between them through the "essence culture" and "outcome culture" dichotomy. This model allows understanding the reason for difference between the European explanation of the term "anxiety" - doubts about the results in life and the Russian explanation of this term - unbearable lack of the life meaning. Namely, the meanings' priorities yield the Russian spirit firmness and heroic moral courage. Disregard of this idea results in pragmatic weakness and historical confusion reflected in certain self-consciousness patterns.

Contemporary research shows the impact of the historical and geographic position, delay in economic integration (in comparison with the political integration) on the Russian self-consciousness development. There should also be mentioned that growth was mainly based not on "pure" politics or economics, but on the political process as a whole incited by the idea to set up a solid, unified multi-ethnic state.

\subsection{Role of sociologic interceptions in the self-consciousness emergence process}

Modern sociologists put special accent on the "self-consciousness" term itself. This concept refers not only to being aware of oneself as an integral unit within a certain environment, but also as a special knowledge bearer. Besides, research shall be aimed at settling matters of the social and cultural area, representing this subject action area. This is due to the fact that the homogeneous basis set is mainly the spiritual basis of Russia unity and integrity.

The investigations performed revealed existence of two trends continuously exerting impact on the Russian people self-consciousness transformations. On the one hand, there is an outspoken support to modern values characteristic of the liberal Western countries, on the other hand - there is a stable complex of "tough problems" resulting in a low individual self-association with the region and the country as a whole. At present, the trend of Western patterns implementation to provide social order in the country is characterized by ambiguity. This is due to the multicultural and multinational peculiarity of the Russian state. However, the impact of reforms is obvious and it has positive results.

The survey performed in 2011 showed that $81 \%$ of Russian respondents were satisfied with their lives (91348 persons have been interviewed), in $2008-66 \%$, in $2009-75 \%$, in $2010-77 \%$. The categories of the survey included evaluation of one's own welfare, the country economic development, subjective perception of one's personal satisfaction and comfort.

Thus, there is an efficient environment for consolidation of certain values aimed at self-consciousness setting up, provided there is a certain satisfaction with one's own living standard. Nevertheless, these indicators and conditions are not solutions to problems referring to self-identification and development of research on personal behavior transformations. New analysis patterns become increasingly necessary. 


\subsection{Difference in the self-consciousness patterns emergence within the Russian state.}

Social self-consciousness reflects the lifestyle and real life patterns of people residing in the Russian state territory. It is expressed in customs and social norms, interests and value trends, self-identification, motivations.

As a result of sociologic operationalization, contemporary researchers appeal to such phenomena as different social groups' interests. Interests and values lay the foundation for social solidarity and set up the national selfconsciousness patterns, and, consequently, the individual self-awareness. Contemporary Russia is characterized by a continuous development of material differentia, of which the study would allow changing the interests and values pluralization mechanisms. At present, such cramps of the society ideological unity as altruism, collectivism, sacrifice give way to personal life arrangement of the Russian people.

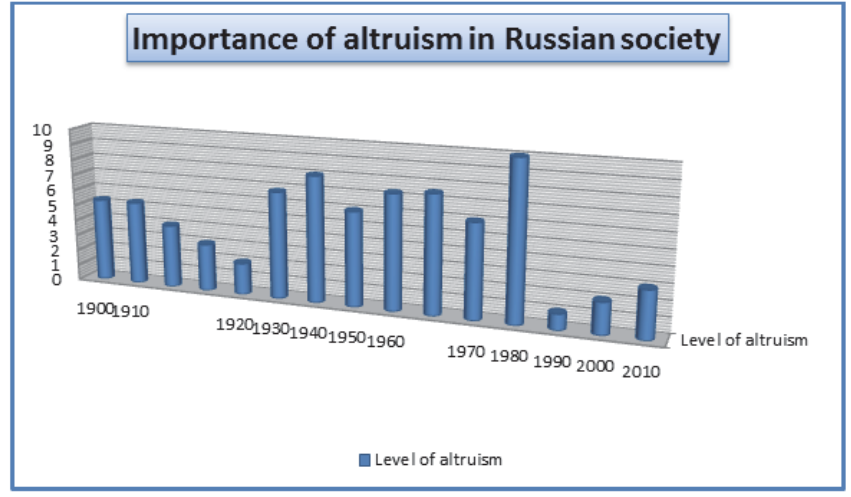

An empirical analysis showed that within most social and demographic groups, except age-classes, there is an increase in individualism aimed at private purposes achievement. Efforts made to improve personal life quality reduce the paternalistic expectations of state, this being a new transformation essentially different from the society personal development patterns characteristic of the Russian state at all previous stages of historical development.

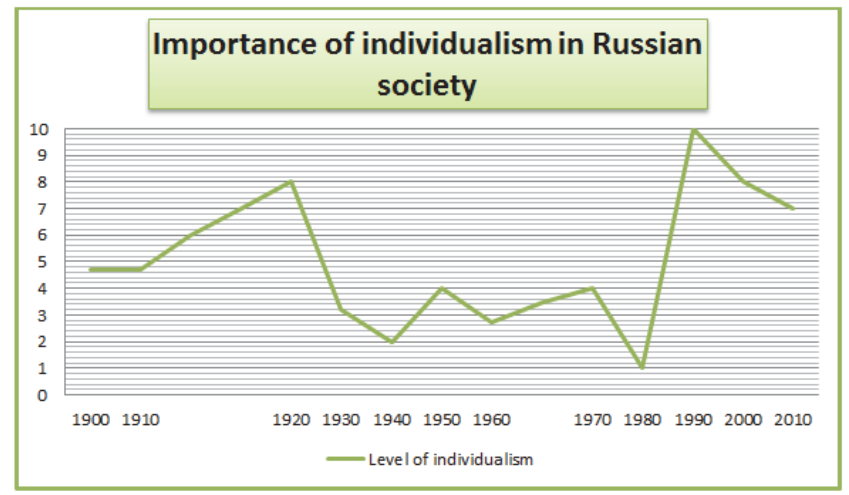

The investigations of 1990-2000 showed differentiation of the living standards and self-consciousness of Russians residing in diverse country regions -primary cities and capitals, ethnic boundary areas, as well as in deep peripheries. Analysis of the country vertical and horizontal structuring provides efficient solutions to problems of diverse selfconsciousness patterns setting up and allows evaluation of social explosions' potential risks even in the context of a relatively favorable economic growth.

The contemporary society self-consciousness is non-homogeneous and determined by a series of objective factors - personal and social being conditions and social atmosphere. Reality showed non-consistency of the theory of social consciousness acknowledgement as something unique. It is structured in accordance with professional, residential, demographic groups and social layers. 


\section{Summary \& Conclusions}

Studying potentially efficient methods of research on the Russian society self-consciousness. Understanding the social content and "nation" concept.

The below notices shall be classified as future provisions aimed at increasing the efficiency of research on selfconsciousness transformations.

Contemporary investigations put an accent on the Russian citizens self-consciousness study referred to as Russian self-consciousness in terms of ethnicity or Russian self-consciousness in terms of the territory inhabited. However, as the Soviet practice shows these two meanings of the term "Russian" are not substitutable. Despite the fact that Russian culture is the basis of Russian self-consciousness, Russian language is the language of the ethnic majority and a means of inter-ethnic communication among Russians.

The phenomenon of the nation emergence refers to the bourgeois revolutions epoch. In the course of the national sovereignty period power was transmitted to the national interaction structure characterized by the ability to act and think together. By that time there was considered that the sovereign nation unity in terms of language and history is a necessary requirement for collective purposes achievement. To attain the desired "unity" of the political community representatives, their values have been subject to rigid constraint under an uncompromising ruling system. Thus, the assimilation policy was set up and consolidated as the democracy regular output similar to the Western model, but based on the socialism ideology.

Emergence of the Russian nation was also based on the society Russification adherent to the czarist Russia period. This epoch described powerful empire as being the most tolerant to the national minorities' descendants. This state was one of the few to view any attractive ethnic group as being socially important and provide vertical mobility channels despite the differences in cultural and personal self-consciousness and values of the great empire ethnic communities in comparison with less developed state entities.

Historical evolvement of social changes in Russia reveals the conception of different trends coexistence. In czarist days and revolutions epoch the self-consciousness of Russians emerged on the basis of cultural homogeneity associated with many national autonomous entities' native cultures. This was the primary reason for non-specific and vague representation of the Russians'self-identification issue.

Appeal to the Soviet past behavior norms development results in social and cultural aspects and its impact on the modern society self-consciousness evolvement.

Researchers often exclude the social period issue from the modern research agenda. At present, the Soviet period may be viewed as a one hundred years period large-scale failure; however, its importance as the Russian people selfconsciousness determinant may not be disregarded.

The Soviet experience may reveal new conceptions of a unique civil nation organization. This period left a great heritage to modern Russian self-consciousness and it should be investigated.

The result of the Bolshevist revolution of 1917 was a new promising administrative and territorial structure in our country. As a result of the national issues settlement, CPSU set up the "soviet ethno-feudalism", later on theoretically justified by Soviet ethnographers and ethnologists. Thus, the nation was reformed from the political and cultural phenomenon to the interrelated "nationality" concept, while the Soviet passport marked the birth of a "new" soviet citizen with a set of values, incentives and behavior norms. Regime attenuation determined the transition of the "nationality" concept from the formal legitimacy and sovereignty instance to a "specific community" concept, often replacing the "selfdetermination" notion. This became the basis for polar-opposite approach to investigations, each of which had a specific interpretation of the personality self-consciousness.

Russia is the single state not drawing lessons from the Soviet federalism experience after the USSR collapse. It did not become ethno-national. The Russian state policy itself aimed at setting up a unique civil nation is still full of contradictions. This state of things would result in a new self-consciousness crisis in the context of self-identification failure, despite a possible federal authority relaxation.

Issue of the soviet national policy enhancement as the self-consciousness crisis basis

The soviet national policy enhancement in the USSR republics and autonomous territories (part of them are now subjects of RF) lead to the setting up of the ethnic intelligentsia class - able to perceive nationalism as an ideology and implement it among the nations representatives. The "high culture" ethnic peculiarity was supported (each republic had its own "great" poet, writer, composer, etc.), although many of the representatives, such as R.Gamzatov, lu. Rithau, Ch. Aytmatov belong to the soviet period Russian culture. The result of the soviet propaganda was the establishment of a consolidated impression of the Russian Empire as the national minorities oppressing state. For this reason, in the 1980s most of the ethnic intelligentsia representatives incited promulgation of the nations' deportation issue during the 
restructuring period. There was an enhancement of the public response. Many ethnic groups got the image of "victims" and later on "enemies", which are at present indispensable elements of most inter-ethnic conflicts. During the post-soviet period, the "unique community" setting up issue specific of contemporary globalization and poly-cultural area emergence got a more and more negative specificity.Not only the Russians, but also "sacrificial" ethnic communities, as well as their interaction ways shall be subject to study.

Taking into account the above-mentioned factors, it becomes obvious that neither the Western models nor the religion-based (namely Christianity-based) patterns are solutions to the national self-consciousness matters in Russia. The second trend promotion would lead to the lack of political loyalty from the part of population and result in another social crisis.

The present-day self-consciousness problems of contemporary Russians result from the difference in concepts' perception by representatives of the soviet via the contemporary "education" categories. The majority of Russian citizens belong to one culture, differing from both the Western culture and the Eastern one. It emerged proceeding from the last centuries' changes, including the soviet period. In researchers' opinion, the state authorities should put an accent on interdiction of traditional ethnic communities' artificial cultivation, consisting of Russian citizens mainly and being part of the unique Russian culture. The unique feature to be taken over from developed liberal states is an equal attitude to all citizens irrespective of the ethnic affiliation. This may become a reliable basis for the emergence of a new, stable population self-consciousness model.

Research includes relevant issues referring to the contemporary Russia population self-consciousness. The analysis is aimed at working out relevant trends and efficient solutions for the research methods improvement and selfconsciousness development principles promotion.

\section{Acknowledgements}

This research is based on works and reports of leading specialists in sociology, psychology, philosophy and pedagogy, in particular: Ladigina O.V. (disp. "National self-consciousness in the context of contemporary social processes: philosophic analysis"), Olishansky D.V. (book "Basic concepts of political psychology. National and ethnic problems in contemporary world"), Popov D.S. (guide "Issue of the contemporary Russian intelligentsia self-cognition: transformation path"), as well as on the results of research works performed by European and American scientists.

\section{References}

Ref.: AbdulatipovR.G. - «Individual. Nation.Society». M.: Science, 1991;

Ref.: IllarionovaT.S. - "Ethnic group: genesis and self-identification issues (diaspora theory)".-M.Noyesleben, 1997;

Ref.: LihacevD.S. - "About the national character of Russians" // Philosophy issues.-1990;

Ref.: MoiseevN.N. -"Universe. Information.Society" - M.: MSU edition, 2001;

Ref.: RubanL.S. - "Inter-ethnic relations and inter-confessional contradictions (regional aspect" //Soc. — 1995;

Ref.: SavosculS.S. -"Post-soviet civil identity in the ethnical aspect”/Этнический аспект постсоветской гражданской идентичности» /1999;

Ref.: TishkovV.A. - "Conceptual evolution of the national policy in Russia" // research on applied and instant ethnology. 1996;

Ref.: TrubetskoyU.S. - "General Eurasian nationalism"// World of Russia - Eurasia: Anthology. — M.: 1995;

Ref.: HabibullinC.N., SkvortsovN.G. -"National self-consciousness testing" -St.Petersburg.:Petropolis, 1993;

Ref.: HorosV. - "Russian idea on the history crossroad". M.:Misli,1989.

Ref.: "State of language in context of Kazakhstan political culture and its peculiarities". 